[Original]

\title{
Predictors of a Desire to be Helpful to Professional Nurses Among Japanese Nursing Assistants in Small- to Medium-Sized Hospitals
}

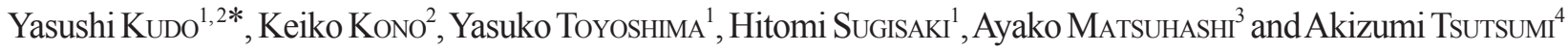 \\ ${ }^{1}$ School of Nursing, Yokkaichi Nursing and Medical Care University, Japan. Yokkaichi, Mie 512-8045, Japan \\ ${ }^{2}$ Research Center for Occupational Health Nursing, Yokkaichi Nursing and Medical Care University, Japan. Yokka- \\ ichi, Mie 512-8045, Japan \\ ${ }^{3}$ Yokohama Nursing School, National Hospital Organization Yokohama Medical Center, Japan. Yokohama, Kanagawa \\ 245-0063, Japan \\ ${ }^{4}$ Department of Public Health, Kitasato University School of Medicine, Japan. Sagamihara, Kanagawa 252-0374, \\ Japan
}

\begin{abstract}
Registered nurses and licensed practical nurses have been educated as professional nurses. Professional nurses can concentrate on their jobs requiring a high degree of expertise with help they get from nursing assistants. If professional nurses have improper attitudes toward nursing assistants, it is most likely that the nursing assistants will not help them to the best of their ability. We investigated nursing assistants' impressions regarding professional nurses' attitudes, and what effects nursing assistants' impressions have on their "desire to be helpful to professional nurses." The study design was a cross sectional study. Twenty-five small- to medium-sized hospitals with 55 to 458 beds were included in this study. The analyzed subjects were 642 nursing assistants (96 males, 546 females). Factor analyses were conducted to extract the factors of nursing assistants' impressions regarding professional nurses' attitudes. Multiple linear regression analysis was conducted to investigate the predictors of "desire to be helpful to professional nurses." We discovered 5 factors: 1. professional nurses' model behavior, 2. manner dealing with nursing assistants, 3. respect for nursing assistants' passion for their work, 4. respect for nursing assistants' work, and 5. enhancing the ability of nursing assistants to do their work. The "desire to be helpful to professional nurses" was significantly associated with "professional nurses' model behavior," "manner dealing with nursing assistants" and "respect for nursing assistants' passion for their work." Factors 1 to 3 are fundamental principles when people establish appropriate relationships. Professional nurses must consider these fundamentals in their daily work in order to get complete cooperation from nursing assistants.
\end{abstract}

Keywords : nursing assistants, registered nurses, licensed nurses, nursing management.

(Received July 31, 2015, accepted April 19, 2016)

\section{Introduction}

Registered nurses and licensed practical nurses have been educated as professional nurses [1]. In contrast, nursing assistants have not received such education [2, $3]$. They do assisting work not requiring expertise under the direction of professional nurses. Professional nurses are able to concentrate on their jobs requiring

\footnotetext{
*Corresponding author: Yasushi Kudo, PhD, Yokkaichi Nursing and Medical Care University, 1200 Kayouchou, Yokkaichi, Mie 512-8045, Japan,
} Tel: +81-59-340-1906, Fax: +81-59-361-1401, E-mail: kudo@y-nm.ac.jp 
a high degree of expertise with the help they get from nursing assistants.

If professional nurses have improper attitudes toward nursing assistants. nursing assistants may hesitate to help them to the best of their ability. Therefore, it is important to investigate Japanese nursing assistants' impressions regarding professional nurses' attitudes, and what effects nursing assistants' impressions have on their "desire to be helpful to professional nurses." However, to our knowledge, such studies have not yet been performed.

Moreover, the Ministry of Health, Labour and Welfare surveyed a number of hospitals in Japan [4]. According to their report, the number of hospitals changes from year to year, but the majority of hospitals in Japan are small- and medium-sized with fewer than 500 beds. It is necessary to collect data for nursing assistants working in those small- and medium-sized hospitals. Therefore, we asked hospitals of those sizes to participate in this study.

In the present study, we investigated nursing assistants' impressions regarding professional nurses' attitudes. We, subsequently, investigated the effects professional nurses' attitudes have on nursing assistants desire to be helpful to professional nurses. We strove to obtain clues to proper nursing management by investigating the associations between professional nurses' attitudes toward nursing assistants and their "desire to be helpful to professional nurses."

\section{Methods}

\section{Definitions of terms}

In the present study, both the registered nurses and licensed practical nurses are called "professional nurses." In the nursing department of the hospital, there are workers who are hired to help registered nurses and licensed practical nurses do their jobs. All such workers are called, "nursing assistants."

\section{Subjects}

Twenty-five hospitals with 55 to 458 beds were included in this study, among which 24 were located in Kanagawa prefecture, and one was in Nagano prefecture. There were 993 Japanese nursing assistants as subjects.

\section{Outline of the questionnaire}

The outline of the questionnaire follows: "basic attributes," "items related to professional nurses," and "degree of satisfaction in work in the subjects limited to certified care workers." We reported on "items related to professional nurses" in the present study. Accordingly, the data of "degree of satisfaction in work in the subjects limited to certified care workers" was not used for the analyses. The questionnaire contents regarding "items related to professional nurses" are shown in the appendix (Original version in Japanese).

Nursing assistants' impressions regarding professional nurses' attitudes

We hypothesized that there are 5 factors among nursing assistants: "manner in dealing with nursing assistants (appendix: 1-4)," "enhancing the ability of nursing assistants to do their work (appendix: 5-8)," "contents of nursing assistants' work (appendix: 9-12)," "nursing assistants' feelings toward their work (appendix: 13-16)," and "professional nurses' model behavior (appendix: 17-20)." These 20 items were all rated on a 7-point scale from "definitely agree" to "definitely disagree."

\section{Desire to be helpful to professional nurses}

A "desire to be helpful to professional nurses" was determined by, "I desire to be helpful to professional nurses in this hospital so that they can concentrate on their work that requires nursing expertise." This item was rated on a 7-point scale from "definitely agree" to "definitely disagree (appendix: 21)."

\section{Basic attributes}

We asked the subjects about age, gender (male/female), employment status (full-time employee / parttime employee), and "certified care worker (yes/no)." A certified care worker is a Japanese professional [5]. They care for the disabled and elderly who require assistance in their daily lives. They are professionals, but they can work as nursing assistants. There is a possibility that they work with model behavior because they have more knowledge related to healthcare than other nursing assistants. We hypothesized that "certified care worker" was significantly positively associated with a "desire to be helpful to professional nurses." 


\section{Distribution and collection of questionnaires}

During the period of February 2014 to mid-March, anonymous self-administered questionnaires, explanatory documents of the study, and envelopes for submission of the completed questionnaires were distributed to the subjects. Approximately 1 week after the distribution, the completed questionnaires were collected in sealed envelopes to ensure that truthful answers were obtained. Those questionnaires were collected in collection boxes in the participating hospitals.

\section{Statistical analyses}

Factor analysis (the principal factor method and promax rotation) of the items concerning nursing assistants' impressions regarding professional nurses' attitudes was performed. The Cronbach's $\alpha$ of each factor of their impressions was also calculated.

We calculated the Pearson's correlation coefficients between "desire to be helpful to professional nurses" and the basic attributes. We also calculated the Pearson's correlation coefficients between "desire to be helpful to professional nurses" and nursing assistants' impressions regarding professional nurses' attitudes.

To investigate the factors associated with "desire to be helpful to professional nurses," standard partial regression coefficients were computed using multiple linear regression analysis. "Desire to be helpful to professional nurses" was a dependent variable. Basic attributes and nursing assistants' impressions regarding professional nurses' attitudes were independent variables.

PASW $^{\circledR}$ Statistics 18.0 was used for all statistical analyses. The significant level was set at $P<0.05$.

\section{Analyzed subjects}

Among 993 questionnaires delivered, 746 were retrieved (collection rate, $75.1 \%$ ). The questionnaires that had one or more missing values in items used in this study were excluded. There were 642 questionnaires for the analyses (response rate, 64.7\%). The average age and standard deviation (SD) of the 642 respondents was $44.1 \pm 12.9$ years old. That of 96 male respondents was $36.5 \pm 12.2$ years old, while that of 546 female respondents was $45.4 \pm 12.6$ years old.

The distributions of participating hospitals and analyzed subjects are shown in Table 1. Twenty-five hospitals from A ( 55 beds) to Y (458 beds) were arranged in order of the number of beds. Among them, 4 hospitals had $<100$ beds, 7 had $100-199$ beds, 8 had 200 -299 beds, 5 had $300-399$ beds, and 1 hospital had $\geqq 400$ beds. Over all, there were more female nursing assistants than males, and there were more full-time employees than part-timers. There were about $20 \%$ who were certified care workers.

\section{Ethics}

Explanations in Japanese of the present study, in addition to the anonymous self-administered questionnaires with return envelopes, were distributed to all of the 993 subjects. The ethics committee of Kitasato University approved this study (No. B13-198).

\section{Results}

The distribution of "desire to be helpful to professional nurses" is shown in Table 2. Regarding "desire to be helpful to professional nurses," 200 (31.2\%) responded "definitely agree," 178 (27.7\%) "agree," 148 (23.1\%) "somewhat agree," 94 (14.6\%) "neither agree nor disagree," 13 (2.0) "somewhat disagree," 3 (0.5\%) "disagree" and $6(0.9 \%)$ "definitely disagree."

Table 3 shows the results of factor loadings of nursing assistants' impressions regarding professional nurses' attitudes. We conducted the factor analyses (the principal factor method and promax rotation) twice as described in the notes in Table 3. We discovered the 5 factors: 1. professional nurses' model behavior, 2. manner dealing with nursing assistants, 3. respect for nursing assistants' passion for their work, 4. respect for nursing assistants' work and 5. enhancing the ability of nursing assistants to do their work. These 5 factors accounted for $71.31 \%$ of the total variance of the 19 items before the rotation, and the eigenvalues of factors 1 to 5 were: $8.334,1.669,1.459,1.071$ and 1.015 respectively.

Table 4 shows the Cronbach's $\alpha$ s of 5 factors of the nursing assistants' impressions regarding professional nurses' attitudes. Cronbach's $\alpha$ s were 0.923 for factor 1 . professional nurses' model behavior, 0.851 for factor 2 . manner dealing with nursing assistants, 0.863 for factor 3. respect for nursing assistants' passion for their work, 0.714 for factor 4 . respect for nursing assistants' work and 0.831 for factor 5 . enhancing the ability of nursing 


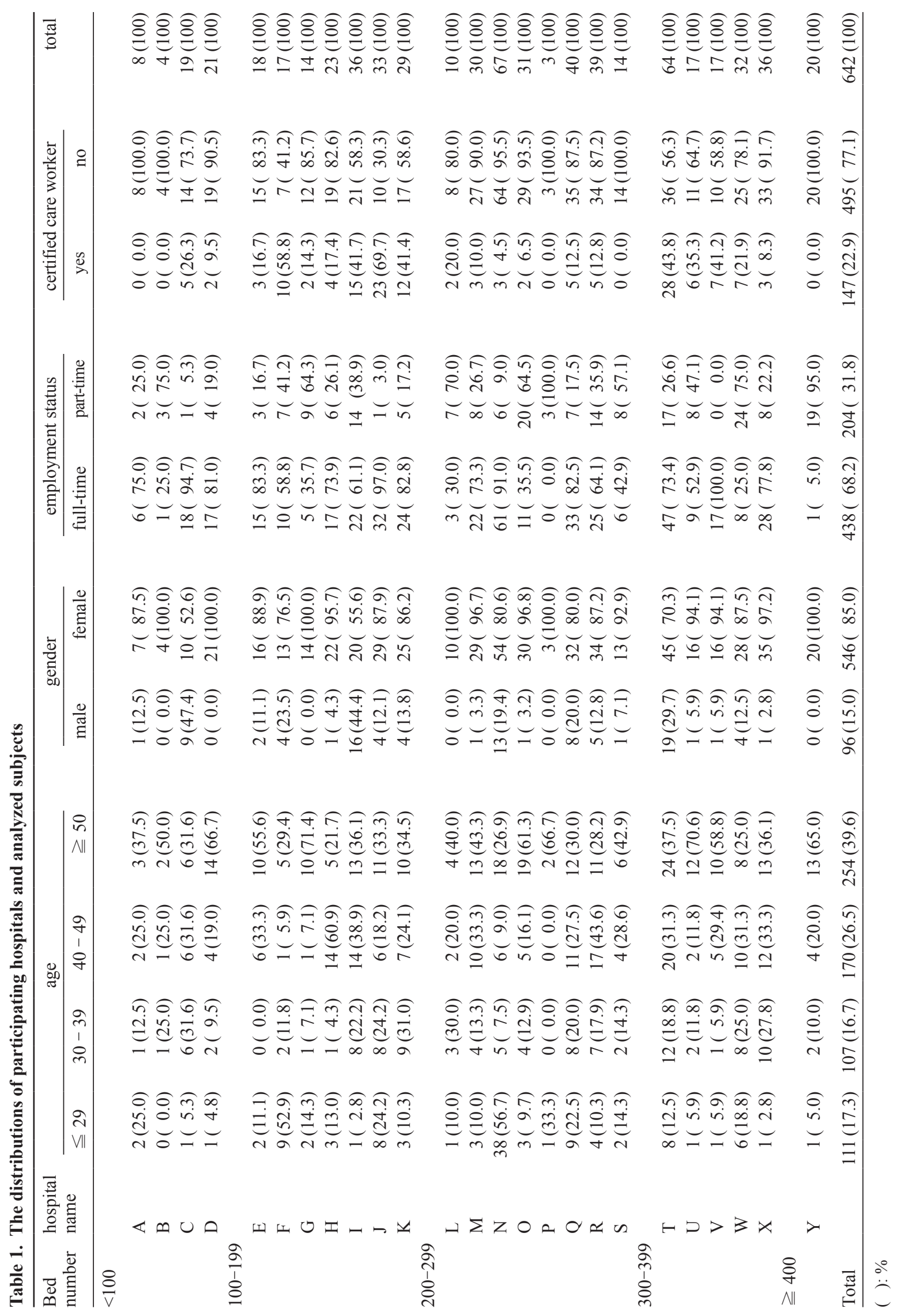


Table 2. Distributions of "desire to be helpful to professional nurses”

\begin{tabular}{lr}
\hline Desire to be helpful to professional nurses & $\mathrm{n}(\%)$ \\
\hline Definitely agree & $200(31.2)$ \\
Agree & $178(27.7)$ \\
Somewhat agree & $148(23.1)$ \\
Neither agree nor disagree & $94(14.6)$ \\
Somewhat disagree & $13(2.0)$ \\
Disagree & $3(0.5)$ \\
Definitely disagree & $6(0.9)$ \\
Total & $642(100)$ \\
\hline
\end{tabular}

Table 3. Factor loadings of nursing assistants' impressions regarding professional nurses' attitudes

\begin{tabular}{|c|c|c|c|c|c|}
\hline Factors & 1 & 2 & 3 & 4 & 5 \\
\hline \multicolumn{6}{|l|}{ 1. Professional nurses'model behavior } \\
\hline 19. Professional nurses' seriousness concerning their work & 0.979 & -0.024 & 0.007 & -0.029 & -0.051 \\
\hline 18. Professional nurses' consideration toward their patients & 0.898 & 0.014 & -0.035 & -0.007 & $|<0.001|^{*}$ \\
\hline 20. Professional nurses' passion for their work & 0.892 & -0.084 & 0.065 & 0.029 & -0.006 \\
\hline 17. Professional nurses' politeness in their manner of working & 0.710 & 0.054 & 0.021 & 0.052 & -0.013 \\
\hline \multicolumn{6}{|l|}{ 2. Manner dealing with nursing assistants } \\
\hline 2. Not being cool toward nursing assistants & -0.113 & 0.945 & -0.016 & 0.029 & -0.064 \\
\hline 3. Not being bossy toward nursing assistants & -0.061 & 0.930 & 0.015 & -0.009 & -0.122 \\
\hline 1. Friendliness & 0.172 & 0.584 & 0.027 & -0.118 & 0.044 \\
\hline 4. Good relationships & 0.215 & 0.543 & 0.066 & -0.094 & 0.172 \\
\hline \multicolumn{6}{|l|}{ 3. Respect for nursing assistants 'passion for their work } \\
\hline 14. Nursing assistants' seriousness concerning their work & 0.013 & 0.008 & 0.879 & 0.014 & -0.018 \\
\hline 13. Nursing assistants' passion for their work & -0.035 & 0.058 & 0.782 & 0.102 & 0.007 \\
\hline 15. Nursing assistants' consideration toward their patients & 0.105 & -0.034 & 0.689 & -0.020 & 0.021 \\
\hline \multicolumn{6}{|l|}{ 4. Respect for nursing assistants'work } \\
\hline 11. Recognizing that thinking is necessary to do nursing assistants' work & 0.047 & 0.012 & -0.073 & 0.905 & -0.139 \\
\hline 12. Nursing assistants' jobs not being miscellaneous & -0.026 & 0.004 & 0.031 & 0.705 & 0.039 \\
\hline 16. Understanding nursing assistants' motivation for choosing this occupation & -0.016 & 0.067 & 0.232 & 0.392 & 0.031 \\
\hline 9. Recognizing that experience is necessary to do nursing assistants' work & -0.012 & -0.153 & 0.151 & 0.364 & 0.053 \\
\hline \multicolumn{6}{|l|}{ 5. Enhancing the ability of nursing assistants to do their work } \\
\hline 6. Opportunities to acquire knowledge & -0.042 & -0.159 & 0.003 & -0.036 & 0.992 \\
\hline 5. Cooperation toward acquiring knowledge & -0.041 & 0.085 & 0.053 & -0.090 & 0.814 \\
\hline 7. Nursing assistants' developing vocational skills & 0.095 & 0.080 & -0.040 & 0.271 & 0.425 \\
\hline 8. Teaching nursing assistants to develop nursing related knowledge & 0.045 & 0.301 & -0.130 & 0.199 & 0.382 \\
\hline
\end{tabular}

Interfactor correlations

1. Professional nurses' model behavior

2. Manner dealing with nursing assistants

3. Respect for nursing assistants 'passion for their work

4. Respect for nursing assistants' work

5. Enhancing the ability of nursing assistants to do their work

*: Because factor loadings can be either positive $(+)$ or negative $(-)$, the absolute value was used. To conduct the factor analyses, the following system was used. Concerning each item of nursing assistants' impressions regarding professional nurses' attitudes (appendix: $1-20), 1$ to 7 points were given from "definitely disagree" to "definitely agree." Factor analysis (the principal factor method and promax rotation) of the 20 items of nursing assistants' impressions regarding professional nurses' attitudes was performed. Factors with eigenvalues of $\geqq 1$ were retained. "Recognizing that nursing assistants' work is important (appendix 10)" had the factor loadings $\geqq|0.35|$ for both factors 3 and 4 . That item, therefore, was excluded. We subsequently conducted factor analysis (the principal factor method and promax rotation) again for the 19 items concerning nursing assistants' impressions regarding professional nurses' attitudes. Bold-faced type shows factor loadings $\geqq 0.35$. 
assistants to do their work.

Pearson's correlation coefficients are shown in Table 5. Males, full-time employees, and certified care workers have a weak desire to be helpful to professional nurses compared with females, part-time employees, and non-certified care workers. As the satisfaction level of each factor (i.e., "professional nurses' model behavior," "manner dealing with nursing assistants," "respect for nursing assistants' passion for their work," "respect for nursing assistants' work," and "enhancing the ability of nursing assistants to do their work") increases, and the "desire to be helpful to professional nurses" is stronger.
Standard partial regression coefficients are also shown in Table 5. Although "gender," "employment status" (full-time/part-time employees), and "certified care worker" (yes/no) had significant correlations with the "desire to be helpful to professional nurses," the standard partial regression coefficient of these three variables became insignificant. The Pearson's correlation coefficient of "respect for nursing assistants' work" was $0.214(P<0.001)$. However, the sign of the standard partial regression coefficient of this factor changed to negative $(\beta=-0.052)$ and became insignificant $(P=0.237)$. The Pearson's correlation coefficient of 'enhancing nursing assistants' ability to do their

Table 4. Means, standard deviations and Cronbach's $\alpha \mathrm{s}$

\begin{tabular}{llll}
\hline Factor & number of items & mean \pm SD & Cronbach's $\alpha$ \\
\hline 1. Professional nurses' model behavior & 4 & $19.48 \pm 4.93$ & 0.923 \\
2. Manner dealing with nursing assistants & 4 & $19.20 \pm 4.99$ & 0.851 \\
3. Respect for nursing assistants' passion for their work & 3 & $13.97 \pm 3.23$ & 0.863 \\
4. Respect for nursing assistants' work & 4 & $17.95 \pm 4.39$ & 0.714 \\
5. Enhancing the ability of nursing assistants to do their work & 4 & $18.40 \pm 4.86$ & 0.831 \\
\hline
\end{tabular}

To calculate the means, standard deviations and Cronbach's $\alpha$ s, regarding the items for each factor shown in Table 3, 1 to 7 points were given in the order from "definitely disagree" to "definitely agree." As shown in Table 3, because the "respect for nursing assistants' passion for their work" was composed of 3 items, the range of the score of each factor per analyzed subject could be from 3 to 21. Because the other factors were composed of 4 items, the range of the score of each factor per analyzed subject could be from 4 to 28. SD: standard deviation

Table 5. Variables associated with "desire to be helpful to professional nurses"

\begin{tabular}{lrrrrr}
\hline Variables & r & $P$ & $\beta$ & $P$ & VIF \\
\hline Age & 0.007 & 0.866 & $<0.001$ & 0.990 & 1.078 \\
Gender & -0.091 & 0.021 & -0.064 & 0.077 & 1.096 \\
Employment status & -0.082 & 0.038 & -0.017 & 0.636 & 1.081 \\
Certified care worker & -0.158 & $<0.001$ & -0.057 & 0.119 & 1.094 \\
Factor 1. Professional nurses' model behavior & 0.456 & $<0.001$ & 0.321 & $<0.001$ & 2.015 \\
2. Manner dealing with nursing assistants & 0.339 & $<0.001$ & 0.111 & 0.020 & 1.847 \\
$\quad$ 3. Respect for nursing assistants' passion for their work & 0.351 & $<0.001$ & 0.104 & 0.030 & 1.883 \\
4. Respect for nursing assistants' work & 0.214 & $<0.001$ & -0.052 & 0.237 & 1.588 \\
5. Enhancing the ability of nursing assistants to do their work & 0.317 & $<0.001$ & 0.032 & 0.520 & 2.025 \\
\hline
\end{tabular}

r: Pearson's correlation coefficient, $\beta$ : standard partial regression coefficient, VIF: variance inflation factor, Adjusted $\mathrm{R}^{2}=0.225$, To calculate Pearson's correlation coefficients and standard partial regression coefficients, the following system was used. Concerning "desire to be helpful for professional nurses," 1 to 7 points were given in the order from "definitely disagree" to "definitely agree." Concerning age, the actual age was used as a continuous variable. The coding of dichotomous variables were: gender (male $=1$, female $=0$ ), employment status (full-time employee $=1$, part-time employee $=0$ ) and certified care worker (yes $=1$, no $=0$ ). Regarding the items for each factor shown in Table 3, 1 to 7 points were given in the order from "definitely disagree" to "definitely agree" and the summed scores of the items for each factor were used. For example, the summed score of "factor 1. professional nurses' model behavior" was the total of the 1 to 7 points given for each item: "17. professional nurses' politeness in their manner of working" + "18. professional nurses' consideration toward their patients" + "19. professional nurses' seriousness concerning their work" + "20. professional nurses' passion for their work." 
work" was significant, but the standard partial regression coefficient of this factor became insignificant.

The desire to be helpful to professional nurses is stronger if professional nurses have model behavior, their manner of dealing with nursing assistants is better, and their respect for nursing assistants' passion for their work is deeper. The adjusted $\mathrm{R}^{2}$ value was 0.225 .

\section{Discussion}

As described in the introduction, professional nurses are able to concentrate on their jobs requiring a high degree of expertise with the help they get from nursing assistants. In the present study, we analyzed nursing assistants' impressions regarding professional nurses' attitudes and then investigated what effects those impressions have on their desires to be helpful to professional nurses.

If there is evidence that the attitudes of professional nurses toward nursing assistants affect their desire to be helpful to professional nurses, this will be useful when the directors of the nursing department give instructions to professional nurses. The provision of such data to professional nurses would change their behavior. We conducted this study because it will be helpful for nursing management.

There are previous studies regarding nurse-physician interaction from the viewpoint of nurses [6-8]. For example, Aiken et al reported the data of 43,329 nurses from the United States (Pennsylvania), Canada, England, Scotland and Germany [6]. Regarding the item, "physicians and nurses have good working relationships," $83.4 \%$ of nurses in Pennsylvania answered "agreeing." As well as, $80.1 \%$ of nurses in Canada, $86.2 \%$ of nurses in England, $85.7 \%$ of nurses in Scotland and $82.7 \%$ of nurses in Germany answered "agreeing." On the other hand, there are also reports of verbal abuse of nurses by physicians [7, 8].

These studies are important to build appropriate relations between nurses and physicians [6-8]. However, nursing assistants are also important for professional nurses. To our knowledge, there are no studies regarding nurse-nursing assistant interaction from the viewpoint of nursing assistants.

As results of factor analyses, 5 factors were extracted: factor 1. "professional nurses' model behavior," factor 2. "manner dealing with nursing assistants," factor 3. "respect for nursing assistants' passion for their work," factor 4. "respect for nursing assistants' work" and factor 5. "enhancing the ability of nursing assistants to do their work." "Desire to be helpful to professional nurses" was significantly related to "professional nurses' model behavior," "manner dealing with nursing assistants" and "respect for nursing assistants' passion for their work."

The first limitation was that there were only 25 hospitals in Kanagawa and Nagano prefectures. Therefore, the generalizability of our results is limited. It will be necessary to enlist the cooperation of hospitals throughout Japan. The second limitation was that because a cross-sectional design was used, it was difficult to identify causal relations.

Although we conducted multiple linear regression analysis, the adjusted $\mathrm{R}^{2}$ value was 0.225 . Therefore, the study of other independent variables is warranted. For example, nursing assistants' job satisfaction affects work motivation [9]. Low job satisfaction may foster complaints about professional nurses, who are the superiors of nursing assistants. If so, even if the attitudes of professional nurses are good, poor job satisfaction may produce adverse effects on the "desire to be helpful to professional nurses."

In addition, it may be important for nursing assistants to investigate their actual tasks and examine the associations between their tasks and "desire to be helpful to professional nurses." Nursing assistants have not received education for nursing professionals [2]. Therefore, if the nursing assistants' tasks are too diversified, they may feel overworked when assisting professional nurses. If so, this may adversely affect their "desire to be helpful to professional nurses."

The "desire to be helpful to professional nurses" was significantly related to factor 1. "professional nurses' model behavior." If professional nurses do not work voluntarily (e.g., politeness in their manner and passion for their work [Table 3 and the Appendix]), nursing assistants would wonder why they have to help professional nurses with their work. Additionally, they might feel the lack of professional nurses' model behavior as disrespectful. Unless professional nurses take the initiative to work themselves, they cannot be sure of getting nursing assistants' cooperation. 
The "desire to be helpful to professional nurses" was significantly related to factor 2 . "manner dealing with nursing assistants." Without the help of nursing assistants, professional nurses cannot devote themselves completely to their work requiring a high degree of expertise. Therefore, professional nurses should feel thankful for nursing assistants and communicate with them in a way that expresses their feelings of gratitude. Nursing assistants would probably have favorable impressions toward professional nurses and feel that their work is rewarding.

"Desire to be helpful to professional nurses" was significantly related to factor 3, "respect for nursing assistants' passion for their work." It is natural that individuals have a desire to be recognized by others when they make great efforts in their work. The contents of work for nursing assistants are limited compared with those for professional nurses. However, even if the contents of work are limited, nursing assistants value the intrinsic nature and experience of their jobs [9]. Respect for nursing assistants' passion for their work is necessary to establish human relationships between nursing assistants and professional nurses.

In summary, factor 1. 'professional nurses' model behavior," factor 2. "manner dealing with nursing assistants," and factor 3. "respect for nursing assistants' passion for their work" are primary fundamentals to build appropriate relationships. When professional nurses require help with their work from nursing assistants, they must consider these fundamentals.

\section{Conflicts of interest}

The authors declare no conflicts of interest.

\section{References}

1. Ishii M (2009): Perfect guide to become a nurse. Shufunotomo, Tokyo 159 pp, http://shufunotomo.hondana. jp/book/b143097.html (in Japanese)

2. Katsumata H (1995): Nursing and "nursing aid." What is nursing aid? Kangotenbou 20: 754-756, http://search. jamas.or.jp/link/bc/19950602810002 (in Japanese)

3. Nagao M, Higashi K, Hirata H, Yuui N, Sasaki H, Yokota Y, Ikeda H \& Komoto H (1997): Handbook of basic care for nursing assistants. Japanese Nursing Associa- tion Publishing, Tokyo 134 pp, http://www.jnapc.co.jp/ products/detail.php?product_id=1037\&PHPSESSID $=\mathrm{e}$ $2760 b f 5 d 31445 c 6785693 \mathrm{c} 4343 \mathrm{~d} 523 \mathrm{c}$ (in Japanese)

4. Ministry of Health, Labour and Welfare (2013): Survey of medical institutions \& hospital report /2013. Ministry of Health, Labour and Welfare, Tokyo. http://www. mhlw.go.jp/toukei/saikin/hw/iryosd/13/ (in Japanese)

5. Terajima A (2011): A book for people aspiring to become certified care workers. (CONDEX Intelligence Institute, ed). Seibido Shuppan, Tokyo 207 pp, ISBN 978-4-415-21021-6, http://www.seibidoshuppan.co.jp/ product/9784415220635/ (in Japanese)

6. Aiken LH, Clarke SP, Sloane DM, Sochalski JA, Busse R, Clarke H, Giovannetti P, Hunt J, Rafferty AM \& Shamian J (2001): Nurses' reports on hospital care in five countries. Health Aff (Millwood) 20 (3): 43-53

7. Brewer CS, Kovner CT, Obeidat RF \& Budin WC (2013): Positive work environments of early-career registered nurses and the correlation with physician verbal abuse. Nurs Outlook 61: 408-416

8. Manderino MA \& Berkey N (1997): Verbal abuse of staff nurses by physicians. J Prof Nurs 13: 48-55

9. Kudo Y, Kido S, Shahzad MT, Yoshimura E, Shibuya A \& Aizawa Y (2011): Work motivation for Japanese nursing assistants in small- to medium-sized hospitals. Tohoku J Exp Med 225: 293-300

\section{Appendix: Items related to professional nurses (Original version in Japanese)}

\section{Friendliness}

1. Professional nurses in this hospital are generally friendly toward nursing assistants.

Not being cool toward nursing assistants

2. Professional nurses in this hospital are not generally cool toward nursing assistants.

Not being bossy toward nursing assistants

3. Professional nurses in this hospital are not generally bossy toward nursing assistants.

Good relationships

4. Professional nurses in this hospital generally have good relationships with nursing assistants. 


\section{Cooperation toward acquiring knowledge}

5. Professional nurses in this hospital are generally cooperative with nursing assistants toward their acquiring knowledge in nursing.

\section{Opportunities to acquire knowledge}

6. Professional nurses in this hospital generally give nursing assistants opportunities to acquire knowledge in nursing.

Nursing assistants' developing vocational skills

7. Professional nurses in this hospital are generally not indifferent toward nursing assistants' developing their vocational skills.

Teaching nursing assistants to develop nursing related knowledge

8. Professional nurses in this hospital generally do not think that teaching nursing assistants to develop nursing related knowledge is bothersome.

Recognizing that experience is necessary to do nursing assistants'work

9. Professional nurses in this hospital generally recognize that experience is necessary for nursing assistants to do their work.

Recognizing that nursing assistants 'work is important

10. Professional nurses in this hospital generally recognize that nursing assistants' work is important.

Recognizing that thinking is necessary to do nursing assistants' work

11. Professional nurses in this hospital generally do not think that nursing assistants' work can be done without thinking.

\section{Nursing assistants' jobs not being miscellaneous}

12. Professional nurses in this hospital generally do not think that nursing assistants' jobs are miscellaneous.
Nursing assistants' passion for their work

13. Professional nurses in this hospital generally think that nursing assistants have passion for their work.

Nursing assistants'seriousness concerning their work

14. Professional nurses in this hospital generally think that nursing assistants are serious about their work.

Nursing assistants' consideration toward their patients

15. Professional nurses in this hospital generally think that nursing assistants are considerate of their patients.

Understanding nursing assistants' motivation for choosing this occupation

16. Professional nurses in this hospital generally do not think that nursing assistants choose their occupation without giving it much thought.

\section{Professional nurses 'politeness in their manner of working}

17. Professional nurses in this hospital are generally polite in their manner of working.

Professional nurses' consideration toward their patients

18. Professional nurses in this hospital are generally considerate of their patients.

Professional nurses'seriousness concerning their work

19. Professional nurses in this hospital are generally serious about their work.

Professional nurses ' passion for their work

20. Professional nurses in this hospital generally are passionate toward their work.

Desire to be helpful to professional nurses

21. I desire to be helpful to professional nurses in this hospital so that they can concentrate on their work that requires nursing expertise. 
中小規模病院に勤務する看護補助者の看護師および准看護師に貢献したい思いに関連する因子

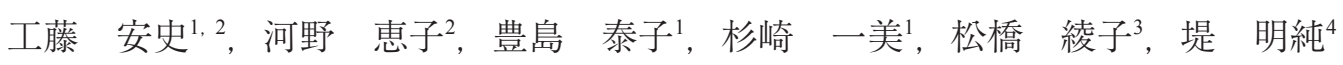

${ }^{1}$ 四日市看護医療大学 看護学部

2 四日市看護医療大学 産業看護研究センター

3独立行政法人 国立病院機構 横浜医療センター附属横浜看護学校

${ }^{4}$ 北里大学 医学部 公衆衛生学

要旨：看護師および准看護師は, 看護専門職者としての教育を受けている。看護専門職者は, 看護補助者に仕 事を手伝ってもらうことで, 専門性の高い職務に集中できる。もし看護専門職者が看護補助者に対して不適切な態 度をとった場合, 看護補助者は, 力の及ぶ限り看護専門職者を助けたいと思う気持ちは生じ難くなりえる.我々は, 看護補助者の看護専門職者に対する心象を調查し, その後, 看護補助者のどのような心象が, 看護専門職者に貢献し たい思いに関連しているのか検討した。研究デザインは横断研究であった．25ケ所の中小規模病院 (55 床から 458 床)が,この研究に参加した。解析対象は642名の看護補助者であった(男性 96 名, 女性 546 名). 看護専門職者の態 度に関する看護補助者の心象を構成する因子を抽出するために因子分析を行った。「看護専門職者に貢献したい思 い」に関する予測因子を探る目的で, 重回帰分析を行った。因子分析の結果, 第 1 因子(看護専門職者の模範となる行 動), 第 2 因子(看護補助者へのマナー), 第 3 因子(看護補助者の仕事への情熱に対する尊重), 第4 因子(看護補助者の 仕事への尊重), 第 5 因子(看護補助者の仕事をする能力の向上)の 5 つの因子が抽出された。「看護専門職者に貢献し たい思い」に対して有意に関連していた因子は, 「看護専門職者の模範となる行動」,「看護補助者へのマナー」, 「看護 補助者の仕事への情熱に対する尊重」であった。これら第 1 因子から第 3 因子は, 適切な人間関係を構築する時の基 本的な原則である. 看護補助者から最大限の協力を得られるためにも, 看護専門職者は, 日々の業務の中で, これら の基本に留意する必要がある.

キーワード : 看護補助者, 看護師, 准看護師, 看護管理.

J UOEH(産業医大誌) 38(2)：119-128（2016） 